Науковий вісник Нлту України
Scientific Bulletin of UNFU
https://nv.nltu.edu.ua
$\begin{aligned} & \text { https://doi.org/10.36930/40310118 } \\ & \text { Article received 23.01.2021 p. } \\ & \text { Article accepted 04.02.2021 p. } \\ & \text { UDC 629.113 }\end{aligned}$

Д. Л. Паращук, В. М. Зіркевич, М. Г. Грубель

Національна академія сухопутних військ ім. гетьмана Петра Сагайдачного, м. Львів, Україна

\title{
МОДЕЛЮВАННЯ ДИНАМІКИ ГАСНИКА КОЛИВАНЬ ІЗ КЕРОВАНОЮ ЧАСТОТОЮ
}

Розроблено методику описання амплітудно-частотної характеристики динамічного гасника коливань, який $є$ пружною консольною балкою із системою зосереджених мас. Математичною моделлю коливань такої системи $є$ крайова задача із дискретною правою частиною. Використовуючи властивості системи власних функцій, які описують форми власних коливань вказаного тіла без зосереджених мас, методом регуляризації отримано аналітичні співвідношення, які описують амплітудо-частотну характеристику такого гасника коливань. Встановлено, зокрема, що його частота власних коливань приймає менші значення для: більших величин зосереджених мас, ближчого їх розміщення до кінця пружного тіла та більшої його довжини. Отримані співвідношення можуть бути базовими для налаштування вказаного типу гасників коливань 3 метою максимального виконання ними функціональних завдань. Ефективність застосування динамічних гасників коливань (ДГК) для гасіння коливань встановленого у транспортному засобі чутливого елемента залежить від багатьох чинників: способів і місця кріплення до підресореної частини транспортного засобу, його розмірів та ваги, матеріалу та його компоновки та ін. Сукупно зазначені чинники впливають на основні характеристики власних і вимушених його коливань, а відтак - на частину енергії, яку отримує ДГК від чутливого елемента, зумовлену рухом транспортного засобу вздовж пересіченої місцевості. Із фізичних міркувань остання значною мірою залежить від співвідношення між частотами власних коливань ДГК, чутливого елемента та підресореної частини. Отримано математичну модель ДГК, яка відповідає консольно закріпленій балці. Способом регуляризації дискретних зовнішніх сил отримано спектр власних частот ДГК, який враховує всі основні його характеристики: пружні властивості балки, ії довжину, величину зосередженої маси. 3 використанням зазначеного вище отримано системи диференціальних рівнянь кутових коливань механічної системи підресореної частини транспортного засобу чутливий елемент - ДГК. Програмна реалізація ії дає змогу: визначити місце закріплення динамічних гасників коливань на турелі; визначити оптимальну масу динамічних гасників коливань; розрахувати оптимальні частоти власних коливань динамічних гасників коливань, закріплених на чутливому елементі, під час дії сили при навантаженні в русі транспортного засобу по пересіченій місцевості. Здійснено дослідження взаємодії турелі 3 динамічними гасниками коливань та обгрунтовано спосіб їх оптимального налаштування для уникнення явищ, близьких до резонансних.

Ключові слова: динамічний гасник коливань; математична модель; спектр власних частот; пружна консольна балка.

\section{Вступ}

Динамічні гасники коливань (ДГК), як механічні системи із зосередженими масами чи розподіленими параметрами, набули широкого застосування у різних галузях машино- і приладобудування, будівельної індустрії, у лісогосподарській галузі. Їх також використовують для гасіння коливань стрілецької зброї, встановленої на бойові броньовані машини (ББМ) під час стрільби "з ходу", адже рухаючись пересіченою місцевістю транспортний засіб, точніше кажучи його не підресорена та підресорена частини, зазнають значних коливань $[9,11]$. Останні передаються на стаціонарно встановлену стрілецьку зброю, а відтак - зменшують ймовірність враження противника. Тому виникає проблема для Збройних Сил України (ЗСУ) у створенні таких відносно малогабаритних ДГК, які б максимально поглинали надлишок небажаної енергії у джерелах коливань і віддавали іï ДГК. Їх особливістю є те, що вони повинні підвищити ефективність використання стрілецької зброї у вузько частотному інтервалі коливань, який близький до частоти коливань підресореної частини.

Об'єкт дослідження - динамічні процеси системи ББМ - чутливий елемент - ДГК.

Предмет дослідження - закономірності впливу конструктивних параметрів ДГК на динаміку чутливого елемента, які описують форми власних коливань вказаного тіла без зосереджених мас.

Мета роботи - визначити оптимальні параметри ДГК задля його ефективної роботи.

Для досягнення зазначеної мети визначено такі основні завдання дослідження: визначити спектр власних частот ДГК та такі співвідношення, що описують закон

\section{Інформація про авторів:}

Паращук Дмитро Леонідович, ст. викладач, кафедра автомобілів та автомобільного господарства. Email: kopchenyi.ua@gmail.com; https://orsid.org/0000-0001-8882-1644

Зіркевич Валентин Миколайович, канд. техн. наук, доцент, начальник навчального відділу, Email: v.zirkevych@ukr.net; https://orsid.org/0000-0003-4113-1560

Грубель Михайло Григорович, канд. техн. наук, доцент, начальник кафедри автомобілів та автомобільного господарства. Email: m.g.grybel@gmail.com; https://orsid.org/0000-0002-4820-6935

Цитування за ДстУ: Паращук Д. Л., Зіркевич В. М., Грубель М. Г. Моделювання динаміки гасника коливань із керованою частотою. Науковий вісник НЛтУ України. 2021, т. 31, № 1. С. 105-109.

Citation APA: Parashchuk, D. L., Zirkevych, V. M., \& Hrubel, M. H. (2021). Simulation of controlled frequency damper dynamics. Scientific Bulletin of UNFU, 31(1), 105-109. https://doi.org/10.36930/40310118 
зміни амплітуди динамічного процесу ДГК залежно від в'язко-пружної сили, які були б базою для налаштування ДГК.

Наукова новизна отриманих результатів дослідження - виконано аналітичний розв'язок із можливими варіантами модифікації ДГК на базі адекватної фізичному процесу математичної моделі системи чутливий елемент - ДГК.

Практична значущість результатів дослідження: отримані результати можуть бути базовими для налаштування роботи ДГК з метою максимального поглинання ними енергії. Справедливість їх підтверджується отриманням у граничному випадку відомих співвідношень, які стосуються власних коливань консольної балки; на практиці отримані результати дадуть змогу визначити параметри ДГК (розміри, вага, місце розташування, значення в'язкого та пружного тертя та ін.).

Аналіз останніх досліджень та публікацій. ДГК із демпферами в'язкого чи сухого тертя набули широкого застосування для гасіння коливань будівельних конструкцій - мостів і башт $[3,5,6,8,12]$. За конструктивними особливостями їх можна поділити на пружинного, маятникового, пластинчастого, балкового, каткових та інших типів. Незалежно від конструктивних особливостей ДГК основним їх призначенням $є$ перерозподіл енергії у системі об'єкт коливання - ДГК, а відтак - питання зовнішніх і внутрішніх резонансів вказаної системи та в'язко-пружні (демпферні) характеристики останнього. Проблема гасіння небажаних коливань за допомогою ДГК значно ускладнюється тоді, коли спектр власних частот об'єкта коливань чи зовнішньої дії $\epsilon$ достатньо широким. Для цього у багатьох працях запропоновано за ДГК приймати пружне тіло (класичну балку чи балку Тимошенко) $[5,12]$.

Однак аналітичне визначення для таких конструкцій ДГК навіть спектра власних частот без урахування в'язко-пружних сил $є$ проблематичною задачею. Труднощі описання процесу значно зростають у резонансних зонах за умови, що ДГК, як пружне тіло, включає в себе: одну або декілька зосереджених мас чи розподілену масу на частині балки-ДГК $[3,10,18]$; із урахуванням сил внутрішнього тертя, які задовольняють лінійну чи нелінійну моделі Фохта. Такі ДГК із демпферами в'язкого чи сухого тертя набули широкого застосування для гасіння коливань великогабаритних конструкцій і для багатьох випадків їх розрахункові моделі розглядали спрощеними - у вигляді звичайних пружинних осциляторів чи осциляторів маятникового типу $[1,15,19]$.

Матеріали та методи дослідження. Принцип роботи ДГК побудований на взаємодії коливань двох або декількох тіл як механічної системи, завдяки перерозподілу енергії. Причому перерозподіл енергії між тілами істотно залежить від співвідношення між частотами їх коливань та внутрішніх сил в'язко-пружного тертя. Розв'язати їх значною мірою можна на базі адекватної фізичному процесу математичної моделі системи стрілецька зброя - ДГК та їі аналітичного розв'язку із можливими варіантами модифікації ДГК на базі останнього. Для цього у роботі ДГК пропонуємо вибирати пружним тілом (класичною балкою) із декількома зосередженими масами, розміщеними вздовж нього. Зазначені типи ДГК певною мірою змінюють габарити системи порівняно з їх аналогом у вигляді систем із зосередже- ними масами, і водночас створюють труднощі із визначення спектра власних частот такого ДГК. Саме співвідношення між ними та частотою коливань джерела енергії визначає ефективність поглинання енергії. До того ж конструктивні особливості його (взаємне розташування зосереджених мас, їх величини) істотно впливають на величини частот власних коливань, а отже, їх розташування може бути базою для вирішення задачі синтезу ДГК. Саме такі питання є предметом розгляду в цій роботі.

\section{Результати дослідження та їх обговорення}

За останні роки набули застосування адаптивні ДГК, принцип роботи котрих побудований на використанні у них додаткового джерела енергії. Останнє повинно збуджувати у ДГК коливальний процес у протифазі до збурювальної сили. Такі адаптивні ДГК повинні мати ланку керування пружним або демпфуючим елементом [7] i для практичного використання потребують значних матеріальних затрат, порівняно з ДГК маятникового чи навіть балкового типів. Запропонований ДГК розглядаємо як пружну горизонтальну консольну балку із закріпленим одним (лівим) кінцем. Довжина іiі $l$, жорсткість на згин EI і погонна маса $\rho$ (рис. 1), вздовж нього розміщені зосереджені маси однакових величин $M$ (для простоти дві: одна - на кінці, а друга - на віддалі $x_{0}$ від початку). Сили в'язко-пружного тертя пропорційні швидкості переміщення балки у ступені $2 s+1$.

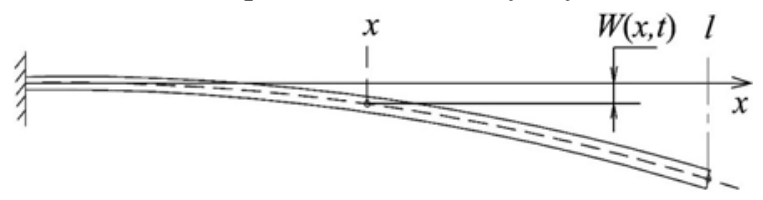

Рис. 1. Модель ДГК без зосередженої маси

Потрібно визначити спектр власних частот такого ДГК та такі співвідношення, що описують закон зміни амплітуди динамічного процесу такого ДГК залежно від в'язко-пружної сили, які були б базою для налаштування ДГК.

Відомо [2, 16], що згинальні коливання однорідної пружної балки сталого поперечного перерізу описуються диференціальним рівнянням

$$
\rho \frac{\partial^{2} w(x, t)}{\partial t^{2}}+E I \frac{\partial^{4} w(x, t)}{\partial x^{4}}=0
$$

за таких крайових умов:

$$
\begin{aligned}
& w(x, t)_{\mid x=0}=0, \quad{\left.\frac{\partial w(x, t)}{\partial x}\right|_{x=0}=0,}_{{\frac{\partial^{2} w(x, t)}{\partial x^{2}}}_{\mid x=l} 0,}^{{\frac{\partial^{3} w(x, t)}{\partial x^{3}}}_{\mid x=l}=0,}
\end{aligned}
$$

де $w(x, t)$ - переміщення у напрямку перпендикулярному до нейтральної осі перерізу балки з Лагранжевою координатою $x$ у довільний момент часу $t$.

У досліджуваному випадку ДГК на пружну балку додатково діятимуть сили ваги зосереджених мас $\mathrm{Mg}$ та їх сили інерції. Величини останніх визначаються зосередженими масами ДГК, пришвидшеннями їх точок прикладання (відповідно $\partial^{2} w\left(x_{0}, t\right) / \partial t^{2}$ та $\left.\partial^{2} w(l, t) / \partial t^{2}\right)$. Зазначені особливості динаміки розглядуваного ДГК найпростіше враховувати у математичній моделі за допомогою $\delta(\ldots)$-функції $[4,14]$. 
Отже, із урахуванням наведеного вище, диференціальне рівняння, яке описує динаміку ДГК, набуває такого вигляду:

$$
\begin{gathered}
\rho \frac{\partial^{2} w(x, t)}{\partial t^{2}}+E I \frac{\partial^{4} w(x, t)}{\partial x^{4}}=\beta\left(\frac{\partial w(x, t)}{\partial t}\right)^{2 s+1}+ \\
+M \delta\left(x-x_{0}\right)\left[g-\frac{\partial^{2} w\left(x_{0}, t\right)}{\partial t^{2}}\right]+M \delta(x-l)\left[g-\frac{\partial^{2} w(l, t)}{\partial t^{2}}\right],
\end{gathered}
$$

де $\beta$-коефіцієнт у силі в'язко-пружного тертя. Щодо крайових умов для рівняння (4), то вони мають вигляд, як і для пружної балки, тобто виражаються співвідношеннями (2) та (3). Особливістю математичної моделі розглядуваного ДГК є те, що права частина рівняння (4) має дискретний характер. Для уникнення труднощів, пов'язаних із знаходженням її розв'язку, використаємо: принцип одночастотності коливань у нелінійних системах із багатьма ступенями вільності та розподіленими параметрами [13]; метод частинної дискретизації за лінійною змінною [17]; ту обставину, що максимальне значення сили в'язко-пружного тертя є малою величиною порівняно 3 іншими внутрішніми силами ДГК; властивості повноти та ортонормованості системи власних функцій, які описують незбурений рух ДГК (коливання пружної балки без зосереджених мас). Останне може бути предметом окремих досліджень і на ньому коротко зупинимось нижче.

Динаміка ДГК без урахування дії зосереджених мас та їх сил інерції, сил в'язко-пружного тертя описується рівнянням (1) за крайових умов (2), (3). Безпосередньою перевіркою переконуємось, що множина його одночастотних розв'язків буде мати такий вигляд: $w(x, t)=X_{k}(x) T_{k}(t)$, де система власних функцій $\left\{X_{k}(x)\right\}$ виражається за допомогою функцій Крилова [14] у вигляді $\left\{K\left(\lambda_{k} x\right)\right\}=\frac{1}{2}\left\{\begin{array}{l}\left(\operatorname{ch} \lambda_{k} x-\cos \lambda_{k} x\right), \\ \left(\operatorname{sh} \lambda_{k} x-\sin \lambda_{k} x\right),\end{array}\right.$ а наближені власних значень $\lambda_{k}$ дорівнюють $\lambda_{1}=1,875 / l, \lambda_{2}=4,694 / l, \ldots$, $\lambda_{n} \approx \frac{2 n-2}{2 l} \pi$. Одночасно власні частоти коливань зазначеної спрощеної моделі ДГК набувають такого вигляду:

$$
\omega_{1} \approx \frac{3,5224}{l^{2}} \sqrt{\frac{E I}{\rho}}, \omega_{2} \approx \frac{22,132}{l^{2}} \sqrt{\frac{E I}{\rho}}, \ldots, \omega_{n} \approx \frac{(2 n-1)}{4 l^{2}} \sqrt{\frac{E I}{\rho}} .
$$

Наведене дає змогу функцію $w(x, t)$ шукати у вигляді такої залежності

$$
w(x, t)=\sum_{i=1} C_{i} K\left(\lambda_{i} x\right) T_{i}(t),
$$

де: $T_{i}(t)$ - невідомі функції; $C_{i}$ - сталі, базою для визначення яких можуть бути початкові умови. Така мішана задача для рівняння (4) може бути предметом окремого розгляду. Щодо крайових умов для функції $w(x, t)$, то вони будуть виконуватись автоматично, адже функції $K\left(\lambda_{i} x\right)$ визначені саме із такої умови, тому перейдемо до визначення функцій $T_{i}(t)$. Для цього способом підстановки залежності (6) у базове рівняння (4) отримуємо

$$
\begin{gathered}
\rho \sum_{i=1} C_{i} K\left(\lambda_{i} x\right)\left\{\ddot{T}_{i}(t)+E I \lambda_{i}^{4}(t) T_{i}(t)\right\}= \\
=\beta\left(\sum_{i=1} C_{i} K\left(\lambda_{i} x\right) \dot{T}_{i}(t)\right)^{2 s+1}+M \delta\left(x-x_{0}\right) . \\
\cdot\left[g-\sum_{i=1} C_{i} K\left(\lambda_{i} x_{0}\right) \ddot{T}_{i}(t)\right]+\delta(x-l)\left[g-\sum_{i=1} C_{i} K\left(\lambda_{i} l\right) \ddot{T}_{i}(t)\right] .
\end{gathered}
$$

Окрім цього, властивості системи функцій $K\left(\lambda_{i} x\right)$ дають змогу $\delta\left(x-x_{0}\right)$ та $\delta(x-l)$ подати відповідно у вигляді:

$$
\delta(x-l)=\frac{1}{\Delta} \sum_{j=1} K\left(\lambda_{j} l\right) K\left(\lambda_{j} x\right), \Delta=\int_{0}^{l} K^{2}\left(\lambda_{i} x\right) d x .
$$

Якщо підставити у залежність (7) на місце $\delta(.$.$) -$ функцій вирази, які узгоджуються із (8), після нескладних перетворень, в основу котрих покладено властивості ортонормованості власних функцій, отримаємо для випадку $s=0$

$$
\left\{\rho+M Q\left[\left(K\left(\lambda_{j} x_{0}\right)+K\left(\lambda_{j} l\right)\right)\right]\right\} \ddot{T}_{i}(t)+E I \lambda_{i}^{4} T_{i}(t)=\beta \dot{T}_{i}(t),
$$

де $Q=\frac{1}{\Delta} \int_{0}^{l} K\left(\lambda_{i} x\right)^{3} d x$.

Диференціальне рівняння (9) визначає спектр власних частот ДГК із системою зосереджених мас (рис. 2), а також закон затухання власних його коливань у вигляді:

$$
\begin{gathered}
\omega_{i}=\sqrt{\frac{E I \lambda_{i}^{4}-0.25 \beta}{\rho+M Q\left[\left(K\left(\lambda_{j} x_{0}\right)+K\left(\lambda_{j} l\right)\right)\right]}} ; \\
a_{i}=a_{i 0} \exp \left(-\frac{0.25 \beta}{\rho+M Q\left[\left(K\left(\lambda_{j} x_{0}\right)+K\left(\lambda_{j} l\right)\right)\right]}\right)
\end{gathered}
$$

де $a_{i 0}-$ початкове значення амплітуди одночастотного динамічного процесу ДГК.

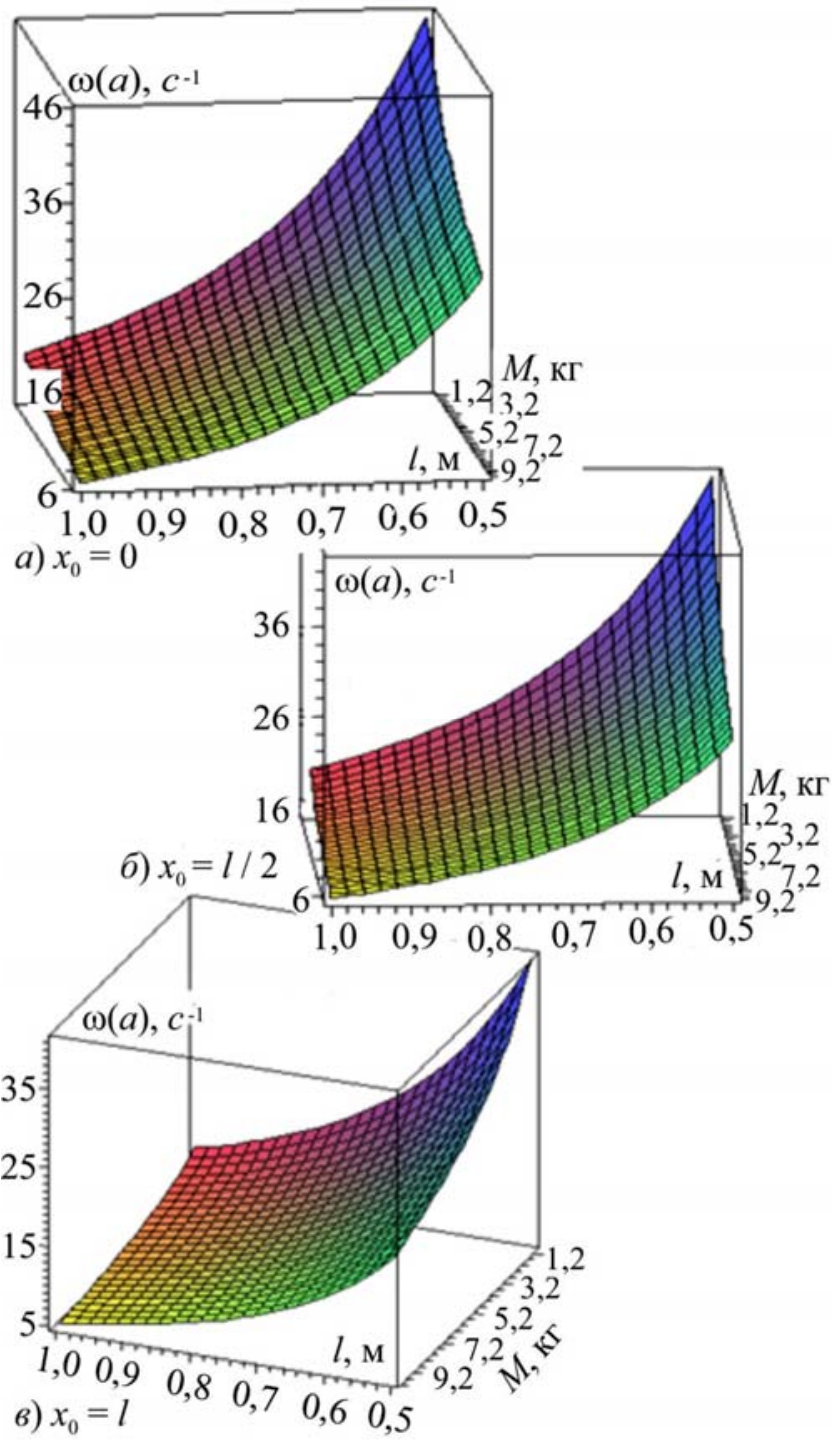

Рис. 2. Залежність головної моди частоти ДГК від параметрів М та 1 
Подані залежності показують, що власна частота коливань ДГК є меншою для:

- більших величин зосереджених мас вантажів; ближчого розташування їх до кінця пружного тіла;

- більших довжин пружного тіла ДГК.

Що стосується нелінійної сили в'язко-пружного тертя за умови малої їі величини останньої, то одночастотний динамічний процес такого ДГК у формі, близькій до головної форми "динамічної рівноваги", описується залежністю $w(x, t)=a(t) K\left(\lambda_{1} x\right) \cos \psi_{1}(t)$, у якій невідомі фун- кції, відповідно до основної ідеї методу Ван-дер-Поля, визначаються системою диференціальних рівнянь.

$\frac{d a}{d t}=\frac{\beta\left(a(t) \omega_{\mid \beta=0}\right)^{2 s+1} \sqrt{\pi}}{\pi l \omega_{\mid \beta=0}} \Gamma\left(\frac{2 s+3}{2}\right) \int_{0}^{l} K^{2 s+1}\left(\lambda_{1} x\right) d x, \frac{d \psi}{d t}=\omega_{\mid \beta=0}$.

Зміну амплітуди згасаючих коливань за різних значень зосереджених мас ДГК та різних значень довжини пружного елемента $l$ зображено на рис. 3,(a-6), а зміну амплітуди згасаючих коливань за різних значень зосереджених мас ДГК та різних значень віддалей зосереджених мас - на рис. 3,(2-e).
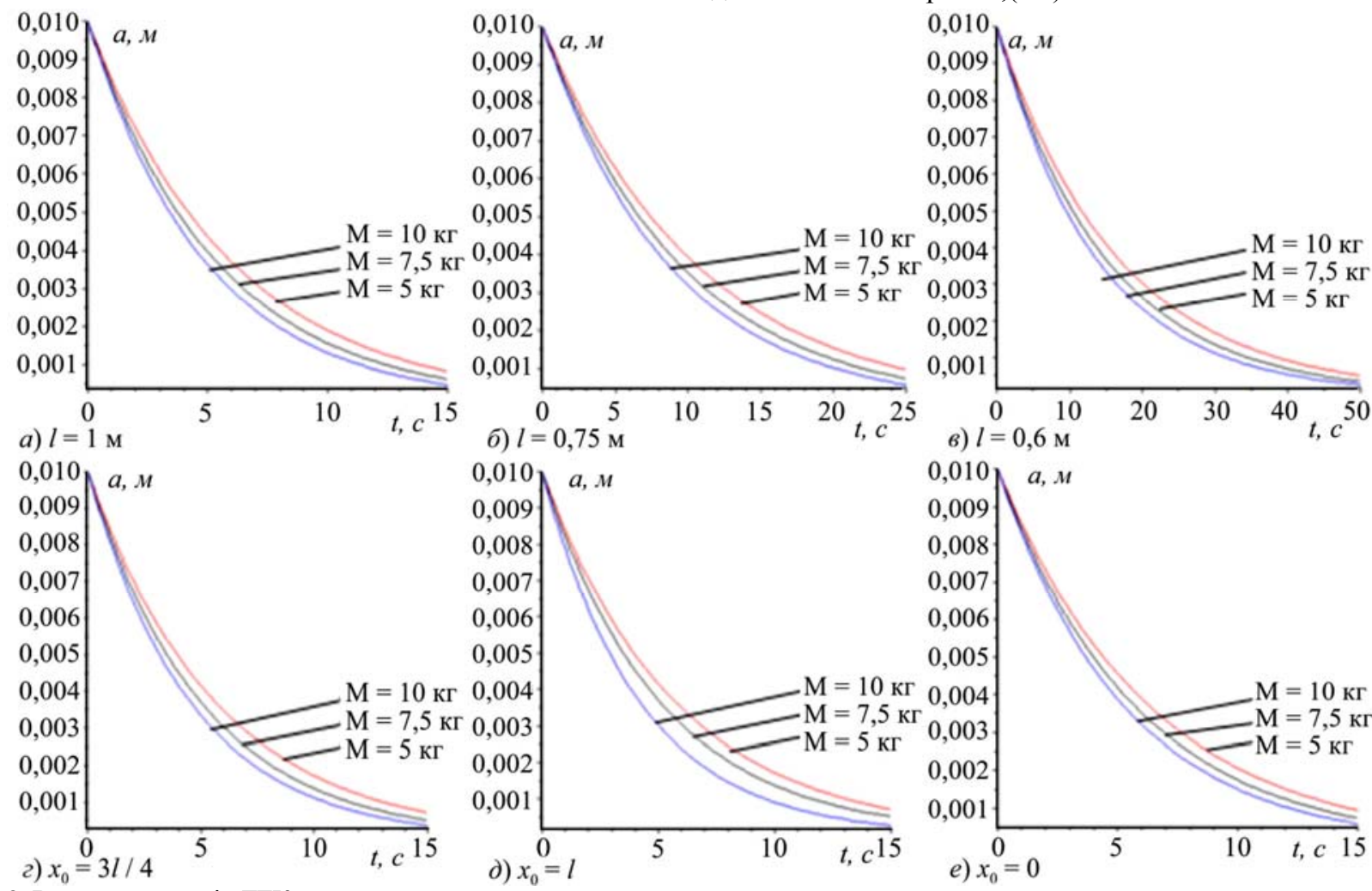

б) $l=0,75 \mathrm{M}$

в) $l=0,6 \mathrm{M}$
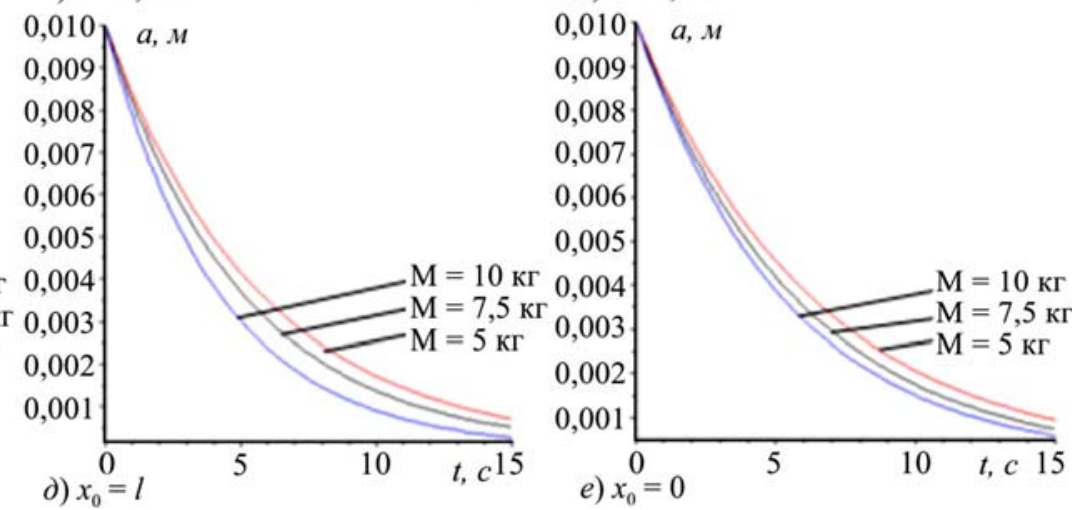

e) $x_{0}=0$

Рис. 3. Вплив параметрів ДГК на затухання коливань

Обговорення результатів дослідження. У роботі описано визначальні параметри коливань ДГК [3, 5], який є пружним тілом із системою зосереджених мас. Математичною моделлю динамічного процесу такої системи є крайова задача із нерегулярною правою частиною. Використання властивостей системи власних функцій, які описують форми власних форм коливань, та методу регуляризації дало змогу отримати: спектр власних частот системи пружне тіло - зосереджені маси; співвідношення, які описують вплив в'язко-пужних сил на динаміку процесу.

Способом аналізу останніх встановлено, що:

- частота власних коливань такого ДГК приймає менші значення для більших величин зосереджених мас, ближчого їх розміщення до кінця пружного тіла та більшої його довжини;

- швидкість затухання амплітуди за однакового закону зміни в'язко-пружної сили $є$ більшою для більших величин зосереджених мас та більшої віддалі між ними.

\section{Висновки}

Для опису ДГК розроблено вдосконалену його фізичну та математичну моделі. Отримано залежність, яка відповідає консольно закріпленій балці із зосередженою масою на кінці. Це дало змогу розрахувати коливання ДГК зі зосередженими масами - звідки отримано системи диференціальних рівнянь кутових коливань механічної системи. Програмна реалізація ії дає змогу:
- визначити місце закріплення динамічних гасників коливань на турелі;

- визначити оптимальну масу динамічних гасників коливань;

- розрахувати оптимальні частоти власних коливань динамічних гасників коливань, закріплених на турелі, під час дії сили при навантаженні за руху ББМ бездоріжжям.

Отримані результати можуть бути базовими для налаштування роботи ДГК з метою максимального поглинання ними енергії. Справедливість їх підтверджується отриманням у граничному випадку відомих співвідношень, які стосуються власних коливань консольної балки.

\section{References}

1. Albert, I., et al. (2002). Analysis of the dynamic reaction of constructive-nonlinear mechanical systems. News VNIIG named after $B$. Vedeneeva, 241, 38-59.

2. Babakov, I. M. (1965). Teoriya kolebanij, $560 \mathrm{p}$.

3. Cherchyk, H., et al. (2012). Parameters identification of particle vibration absorber for rotating machines, (pp. 08-12).

4. Delta function. (2020). Mathematics. Retrieved from: https//math world.wolfram.com/DeltaFunction.html.

5. Demedetskaia, V. V. (2014). Svobodnye kolebaniya vyazkouprugoy balki Timoshenko $\mathrm{s}$ dinamicheskim gasitelem kolebaniy $\mathrm{i}$ sosredotochennymi massami. Bulletin of Dnipropetrovsk National University. Ser. Mechanics, 18(2)7, 66-80. [In Russian].

6. Demedetskaia, V. V., \& Manevych, A. Y. (2011). Theoretical Foundations 12 of Civil Engineering. Polish - Ukrainian Transactions, 19, 161-168. [In Russian]. 
7. Diveev, B. M. (2012). UA 75663, State Intellectual Property Service of Ukraine, $236 \mathrm{p}$.

8. Diveev, B. M., et al. (2014). Zmenshennya amplitudi kolivan za dopomogoyu kombinovanikh dinamichnikh gasnikiv kolivan. Vibrations in engineering and technology, 4(76), 5-9. [In Ukrainian].

9. Dushchenko, V. V. (2007). Disadvantages, reasons for their occurrence and contradictions in the development of the known physical principles of action of elastic elements of suspension systems for military tracked and wheeled vehicles. Vestnik NTU "KhPI", 33, 46-52. [In Russian].

10. Hashchuk, P., et al. (1999). Zastosuvannya diskretno-kontinualnikh diskretnikh skhem dlya viznachennya vibronapruzhen $\mathrm{v}$ mekhanichnikh konstruktsiyakh. Proceedings of the National Polytechnic University, 2(8), 34 41. [In Ukrainian].

11. Hrubel, M. H., Nanivskyi, R. A., \& Sokil, M. B. (2015). Resonance of the addressable part of the collegiate transport units in the hour of the collapse of the orderly system of irregularities. Visnyk Vinnytskoho politekhnichnoho instytutu, 1, 155-161. [In Ukrainian].

12. Kuzio, I. V., et al. (2007). Dinamika velikogabaritnogo podovgastogo elementa mobilnikh mashin. Optimization of production processes and technical control in mechanical engineering and instrument making, 583, 48-51. [In Ukrainian].
13. Mitropolsky, Y. A. (1976). Asimptoticheskie resheniya uravnenij v chastnykh proizvodnykh, $584 \mathrm{p}$.

14. Oleynik, O. A. (2005). Lectures on partial differential equations. Moscow: Binomial, $320 \mathrm{p}$.

15. Palazzo, B., \& Pettia, L. (1997). Aspects of passive control of structural vibrations. Meccanica, 32, 529-544.

16. Ponomarev, S. D. (1980). Raschet uprugikh elementov mashin $i$ priborov. Mashinostroenie, $326 \mathrm{p}$. [In Russian].

17. Sokil, B. I., et al. (2020). Advanced asymptotic approaches and perturbation theory methods in the study of the mathematical model of single-frequency oscillations of a nonlinear elastic body. Mathematical modeling and computing, 7(2), 269-277.

18. Sokil, M., et al. (2018). Methodology for Increasing the Efficiency of Dynamic Process Calculations in Elastic Elements of Complex Engineering Constructions. Spong Underactuated mechanical systems, (pp. 123-130).

19. Vikovich, I. A., et al. (2014). Zastosuvannya riznogo tipu mayatnikovikh dinamichnikh gasnikiv kolivan. Scientific notes. Interuniversity collection (by fields of knowledge Mechanical Engineering and Metalworking, Engineering Mechanics, Metallurgy and Mat erials Science), 45, 79-84.

D. L. Parashchuk, V. M. Zirkevych, M. H. Hrubel

Hetman Petro Sahaidachnyi National Army Academy, Lviv, Ukraine

\section{SIMULATION OF CONTROLLED FREQUENCY DAMPER DYNAMICS}

A method for describing the amplitude-frequency characteristic of a dynamic vibration damper, which is an elastic cantilever beam with a system of concentrated masses, has been developed. The mathematical model of oscillations of such a system is a boundary value problem with a discrete right-hand side. Using the properties of the system of eigenfunctions, which describe the forms of natural oscillations of the specified body without concentrated masses, the regularization, analytical relations that describe the amplitude-frequency characteristic of such an oscillation damper have been obtained. Its natural frequency is revealed to take smaller values for the following: larger values of concentrated masses, their closer placement to the end of the elastic body and its greater length in particular. The obtained ratios can be standard for adjusting the specified type of vibration dampers in order to maximize their functional tasks. The effectiveness of dynamic vibration damper to dampen the oscillations of the sensing element installed in the vehicle depends on many factors, namely: methods and place of attachment to the sprung part of the vehicle, its size and weight, material and its layout, etc. Taken together, these factors affect the main characteristics of their own and forced oscillations, and thus, the part of the energy received by the dynamic vibration damper from the sensing element due to the movement of the vehicle along the rough terrain. For physical reasons, the latter largely depends on the relationship between the natural frequencies of the dynamic vibration damper, the sensing element, and the sprung part. A mathematical model of dynamic vibration damper is obtained, which corresponds to the cantilevered beam. By regularization of discrete external forces, the natural frequency spectrum of dynamic vibration damper is obtained, which considers all its main characteristics such as elastic properties of the beam, its length, and the value of the concentrated mass. Using the mentioned above, the system of differential equations of angular oscillations of the mechanical system of the sprung time of the vehicle - a sensitive element - dynamic vibration damper has been received. Its software implementation allows: to determine the place of fixing of dynamic vibration dampers on the turret; determine the optimal mass of dynamic vibration dampers; calculate the optimal frequencies of natural oscillations of dynamic vibration dampers fixed on the sensing element during the action of force during loading in the movement of the vehicle on rough terrain. The study of the interaction of the turret with dynamic vibration dampers has been carried out and the method of their optimal adjustment in order to avoid the phenomenon close to resonant has been justified.

Keywords: dynamic vibration damper; mathematical model; natural frequency spectrum; elastic cantilever beam. 